\title{
Efektivitas Instalasi Pengolahan Air Limbah pada Effluent Treatment Unit (ETU) PT Lotte Chemical Titan Nusantara
}

\author{
Frebhika Sri Puji Pangesti ${ }^{*}$, Anis Masyruroh², M.Hikmatiar ${ }^{3}$ \\ 1,2,3 Program Studi Teknik Lingkungan,Fakultas Teknik,Universitas Banten Jaya \\ Jalan Ciwaru II No.73 Kota Serang \\ *Koresponden email: frebhikasripujipangesti@unbaja.ac.id
}

Diterima : 25 Mei 2018

Disetujui: 30 Agustus 2018

\begin{abstract}
PT Lotte Chemical Titan Nusantara (PT LCTN) is a Korean Foreign Investment Company in Cilegon City which is a polythylene producing industry. PT LCTN produces waste water into the sea. Wastewater treatment refers to the Decree of the Minister of Environment Number 22 of 2011 on the Permit for Disposal of Wastewater into the Sea of PT Titan Petrokimia Nusantara. The purpose of the research is to identify the problem and the improvement step in wastewater treatment. The effectiveness of wastewater treatment performance at ETU (Effluent Treatment Unit) in 2015, especially on test parameters such as Total Dissolved Solid, TSS (Total Suspended Solid), Nitrate, Nitrite, BOD (Biochemical Oxygen Demand) and COD (Chemical Oxygen Demand). Statistical analysis SPSS Version 22 shows the average value of inlet and outlet there is a difference because the value of $\mathrm{t}$ arithmetic is smaller than $\mathrm{t}$ table. In other words can give a significant influence on the inlet and outlet. Percentage effectiveness of TDS reach 33,33\%, TSS reach 91,67\%, nitrate reach 25\% while for nitrite reach $83,33 \%$.
\end{abstract}

Keywords : Effectiveness of WWTP, effluent treatment unit,waste-water

Abstrak. PT Lotte Chemical Titan Nusantara (PT LCTN) adalah Perusahaan Penanaman Modal Asing Korea di Kota Cilegon yang merupakan industri penghasil polythylene. PT LCTN menghasilkan air limbah yang dibuang ke laut. Pengolahan air limbah merujuk pada peraturan Keputusan Menteri Lingkungan Hidup Nomor 22 Tahun 2011 Tentang Izin Pembuangan Air Limbah ke Laut PT Titan Petrokimia Nusantara. Tujuan penelitianuntuk mengindetifikasi permasalahan dan langkah perbaikan pada pengolahan air limbah. Perhitungan efektivitas terhadapkinerja pengolahan air limbah di ETU (Effluent Treatment Unit) tahun 2015, khususnya terhadap parameter uji seperti TDS (Total Disolved Solid), TSS (Total Suspended Solid), Nitrat, Nitrit, BOD (Biochemical Oxygen Demand) dan COD (Chemical Oxygen Demand). Analisis statistik SPSS Versi 22 menunjukkan nilai rata-rata inlet dan outlet terdapat perbedaan karena nilai t hitung lebih kecil daripada $t$ tabel. Perbedaan ini memberikan pengaruh yang signifikan terhadap inlet dan outlet. Persentase efektivitas TDS mencapai 33,33\%, TSS mencapai 91,67 \%, nitrat mencapai 25\% sedangkan untuk nitrit mencapai 83,33\%.

Kata Kunci: Efektivitas IPAL, Effluent Treatment Unit, Air Limbah

\section{Pendahuluan}

Pertumbuhan penduduk di Indonesia khususnya di perkotaan yangbegitu cepat memberikan dampak yang sangat serius terhadap daya dukung lingkungan. Seiring dengan semakin meningkatnya populasi manusia dan bertambah banyaknya kebutuhan masyarakat, semakin bertambah pula industri yang bermunculan.Kebutuhan industri merupakan salah satu sektor ekonomi yang bertujuan untuk meningkatkan kesejahtraan masyarakat dalam 


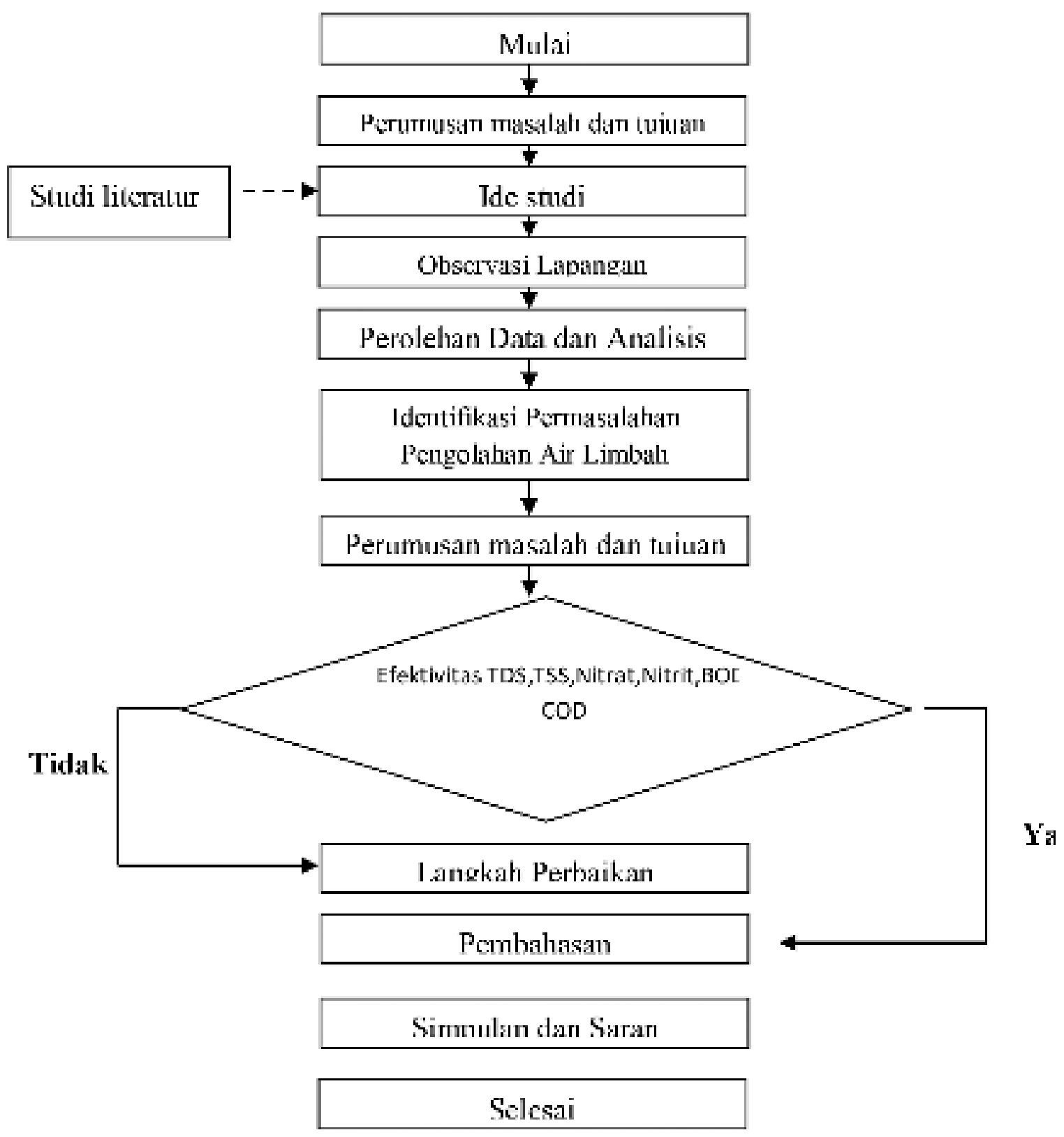

Gambar 1. Bagan alir pengolahan dan analisis data

rangka menghasilkan produk yang berkualitas dan ramah lingkungan. Semakin besar laju perkembangan industrialisasi mengakibatkan terjadinya penurunan kualitas lingkungan khususnya kualitas air. Permasalahan air limbah menjadi sangat populer dikalangan para pelaku industri maupun pemerintah dan masyarakat.

Kota Cilegon merupakan kota yang memiliki berbagai macam jenis sektor industri. Saat ini sektor industri memiliki teknologi pengolahan air limbah yang semakin canggih sehingga dapat meminimalisasi terjadinya pencemaran. Industri di Cilegon yang bergerak di petrokimia salah satunya adalah PT Lotte Chemical Titan Nusantara (PT LCTN). PT LCTN adalah perusahaan Penanaman Modal Asing (PMA) Korea yang merupakan industri penghasil polythylene. Dalam proses produksi,PT LCTN menghasilkan air limbah yang akan mengalir ke badan air yaitu air laut. Sebelum dibuang ke air laut air limbah tersebut diolah terlebih dahulu pada Instalasi Pengolahan Air Limbah (IPAL) di PT LCTN yaitu Effluent Treatment Unit (ETU).

Keberadaan ETU berfungsi untuk memperbaiki kualitas air limbah, mengurangi bahan pencemar serta mengembalikan mutu air limbah 


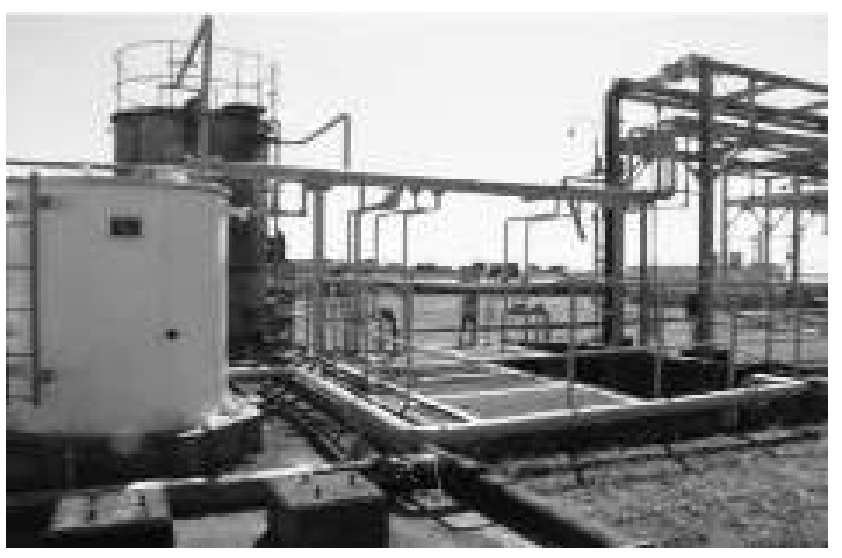

Gambar 2. CPI Separator pada proses ETU

menjadi air dengan baku mutu yang sesuai dengan standar yang tercantum dalam Keputusan Menteri Lingkungan Hidup Nomor 22 Tahun 2011 Tentang Izin Pembuangan Air Limbah ke Laut PT Titan Petrokimia Nusantara. Kepedulian dalam pengolahan air limbah di ETU dilakukan dengan pengambilan sampel uji pada Inlet ETU dan Outlet ETU oleh Laboratorium terakreditasi. Parameter uji yang dilakukan berpedoman pada peraturan terkait dan izin IPLC PT LCTN.

Kondisi akhir existing ETU saat ini sebagian besar parameter uji telah memenuhi baku mutu yang telah ditetapkan dalam izin. Existing ETU yang sudah memenuhi baku mutu, belum pasti memiliki pengolahan yang efektif pada masingmasing unit pengolahan air limbah. Berdasarkan uraian tersebut perlu dilakukan identifikasi kendala atau permasalahan-permasalahan dan perhitungan efektivitas terhadap kinerja pengolahan air limbah di ETU selama periode tahun 2015. Tingkat efektivitas menunjukkan persentase (\%) keberhasilan dalam pengolahan air limbah pada ETU. Parameter yang akan diuji adalah TDS (Total Dissolved Solid), TSS (Total Suspended Solid), Nitrat, Nitrit, BOD (Bioechemical Oxygen Demand) dan COD (Chemical Oxygen Demand) yang diambil pada inlet ETU dan outlet ETU.

\section{Metode Penelitian}

Jenis penelitian yang digunakan adalah studi observasional dan eksperimental. Penelitian dilakukan untuk mengetahui pengolahan air limbah yang paling efektif dan dapat membuat effluent yang dihasilkan industri petrokimia memenuhi baku mutu. Sehingga dapat diketahui sistem pengolahan limbah yang efektif, selanjutnyauntuk mengetahui tingkat efektivitas sistem pengolahan air limbah yang digunakan dilakukan dengan cara mengukur tingkat penyisihan parameter, yang diukur dari pemeriksaan limbah cair sebelum diolah (inlet) dan setelah diolah (outlet). Hasil yang didapatkan dari tingkat efektivitas sistem pengolahan air limbah dinyatakan dalam bentuk persentase $(\%)$.

Variabel yang ditinjau dari sistem pengolahan air limbah dan efektivitas ETU PT LCTN yaitu 6 (enam) parameter uji utama dari 33 (tiga puluh tiga) parameter yang terlampir Keputusan Menteri Lingkungan Hidup Nomor 22 Tahun 2011 Tentang Izin Pembuangan Air Limbah ke laut PT Titan Petrokimia Nusantara. Variabel penelitian adalah hal-hal yang menjadi objek penelitian, yang ditatap dalam suatu kegiatan penelitian, yang menunjukkan variasi, baik secara kuantitatif maupun kualitatif (Arikunto, 2006).Variabel tersebut diantaranya parameter uji seperti TDS (Total Disolved Solid), TSS (Total Suspended Solid), Nitrat, Nitrit, BOD (Biochemical Oxygen Demand) dan COD (Chemical Oxygen Demand).

Pengambilan sampel air limbah baik inlet maupun outlet dilakukan oleh pihak laboratorium terakreditasi. Alat yang dipersiapkan yaitu ember/ sejenisnya, botol sampel, spidol, termometer dan $\mathrm{pH}$ meter.

Perhitungan nilai efektivitas dilakukan agar diketahui tingkat efektif dari sistem pengolahan instalasi pengolahan air limbah (IPAL) dalam mengolah limbah cair sebelum dialirkan ke badan air.Rumus analisis efektifitas IPAL menurut Soeparman dan Suparmin, 2001 adalah sebagai berikut :

$$
\text { \%Efckivitus }=\frac{(A-B)}{A} \times 100 \%
$$

$\mathrm{A}=$ Kadar parameter pada inlet

$\mathrm{B}=$ Kadar parameter pada outlet

Nilai efisiensi digunakan untuk menentukan besarnya persentase penurunan BOD sebelum dan sesudah masuk pengolahan. Efisiensi akan diketahui setelah penelitian dilakukan, semakin 
besar nilai konstanta reaksi tingkat pertama semakin besar efisiensinya. Nilai efisiensi yang diambil adalah nilai rata-rata pengolahan TSS dan BOD (Metcalf \& Eddy,1991).

Pengolahan data dilakukan dengan cara mendeskripsikan temuan-temuan terhadap kendala atau permasalahan yang terjadi di proses pengolahan air limbah unit ETU. Selain itu pemeriksaan sampel limbah cair sebelum pengolahan (inlet) dan limbah cair setelah pengolahan (outlet). Perhitungan efektivitas pengolahan air limbah dilakukan dengan metode perhitungan kuantitatif dengan data analisa inlet dan outlet dinyatakan dalam persentase. Perhitungan efektivitas Microsoft Excel dan program SPSS (Statistical Package for Social Sciences)

\section{Hasil Dan Pembahasan}

\subsection{Tahapan Pengolahan Air Limbah di ETU terdiri dari}

a. Main lagoon

Main lagoon merupakan kolam pengumpul utama dari hasil semua kegiatan proses produksi dengan volume sebesar $96 \mathrm{~m}^{3}$ dan waktu tinggal selama 12 jam. Kolam main lagoon berdimensi 12000 x 8000 x $3600 \mathrm{~mm}$. Kolam ini berisi air, minyak, pellet dan bubuk pellet. Main lagoon menggunakan proses fisika seperti adanya penyaringan atau perangkap (interceptor) untuk material yang mengendap atau mengapung (proses sedimentasi). Pengolahan fisika antara lain dengan menggunakan screen, sieves, dan filter yaitu pemisahan dengan memanfaatkan gaya gravitasi (sedimentasi dan water sparator) serta flotasi, adsorbsi, dan stripping (Sakti A.Siregar,2005)

Beberapa permasalahan di main lagoon adalah :

- Tidak ada alat ukur debit inlet

- Terlihat padatan yang terapung seperti pellet (tidak tersaring sempurna)

- Interceptor (alat penyaring) tidak terawat sehingga padatan ikut terbawa mengalir.

- Terdapat endapan lumpur yang menghalangi kerja dari interceptor

- Saluran pipa overflow menuju CPI Separator sering tersumbat sehingga mengakibatkan air dapat meluap.

b. CPI (Corrugated Plate Interceptor) Separator

CPI merupakan proses fisika yang berfungsi untuk memisahkan kandungan air dengan minyak atau lemak atau oli. Kandungan minyak atau lemak dalam air yang tinggi dapat menghambat tranfer oksigen di dalam bak aerasi yang dapat menyebabkan kinerja ETU kurang maksimal.

Beberapa permasalahan yang terjadi pada pengoperasian CPI Separator unit ETU, diantaranya sebagai berikut :

1. Masih terdapat padatan yang terbawa ke CPI

2. Kondisi pompa yang tidak berjalan karena rusak dan tidak terawat

c. Aerated Lagoon

Aerated Lagoon menerima buangan dari septik tank dan clarified water sump. Air kotor yang berasal dari kamar mandi, toilet dan dapur akan dikumpulkan dalam transfer pit dan kemudian dipompa ke septik tank (central foul water). Air ini kemudian disalurkan ke laut, kecuali apabila overflow akan masuk ke aerated lagoon. Begitu pula dengan clarified watersump proses overflow akan masuk ke aerated lagoon melalui pompa. Sebagian lumpur akan dibuang ke badan air laut melalui bak kontrol.

Beberapa permasalahan yang terjadi pada pengoprasian Aerated Lagoon unit ETU, diantaranya sebagai berikut :

- Agitator untuk pengadukan air limbah tidak berjalan sesuai waktu yang sudah ditentukan

- Kondisi pompa yang tidak berjalan karena rusak dan tidak terawat

- Secara visual terlihat lumpur aktif tidak berfungsi dengan baik

d. Bak Kontrol

Bak ini berfungsi untuk menampung air limbah dan menjadi alat ukur debit (flow meter) 


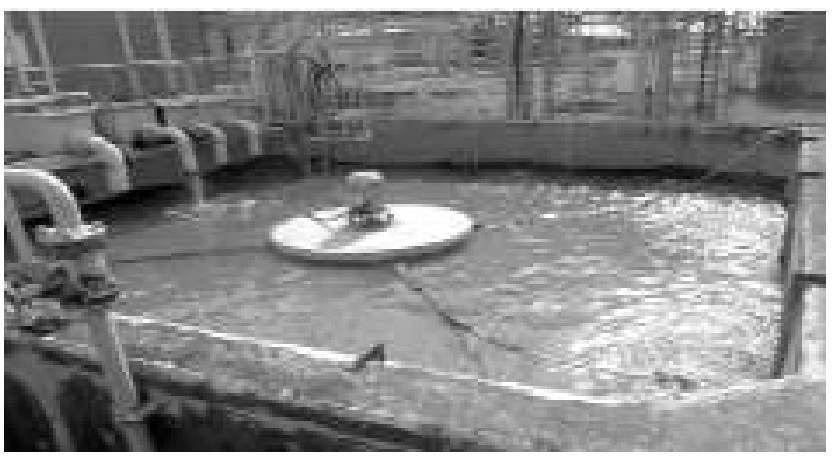

Gambar 3. Kolam Aerated Lagoon pada proses ETU

limbah cair sebelum dibuang ke laut. Terdapat celah segitiga sama kaki terbalik dengan sudut $60^{\circ}$ yang diletakkan melintang terhadap penampang saluran air. Bak kontrol menjadi sampling point atau lokasi pengambilan air limbah setelah proses (outlet).

Beberapa permasalahan yang terjadi pada pengoperasian bak kontrol unit ETU, diantaranya sebagai berikut :

- Tidak terdapat indikator untuk tes air limbah

\subsection{Efektivitas Pengolahan Air Limbah PT LCTN}

Pengambilan sampel air limbah dilakukan pada inlet yaitu kondisi air limbah sebelum diproses pada pengolahan, dan outlet yaitu kondisi air limbah setelah diproses. Pengambilan sampel inlet pada proses kolam main lagoon sedangkan sampel outlet diambil pada bak kontrol. Pengambilan sampel dilakukan setiap bulan sekali. Uji analisa dilakukan oleh pihak ketiga yaitu PT Sucofindo International Cilegon. Baku mutu analisa merujuk Keputusan Menteri

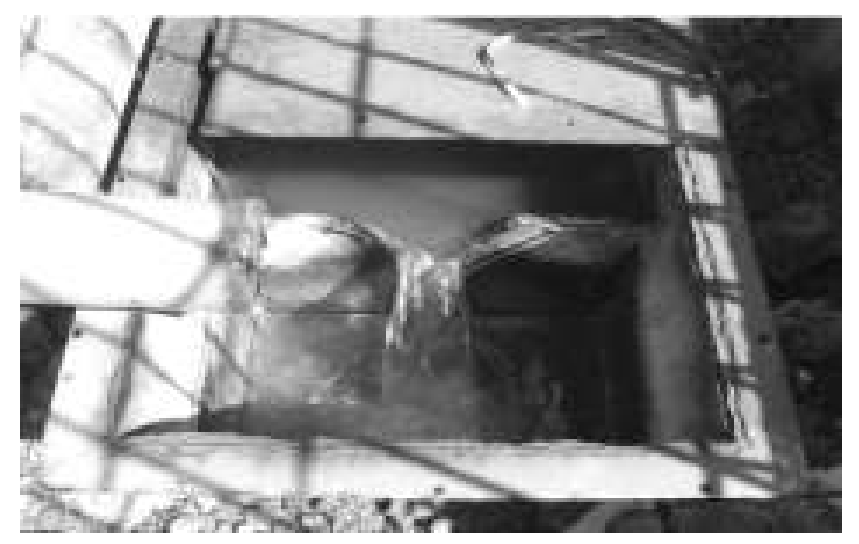

Gambar 4. Bak kontrol pada proses ETU

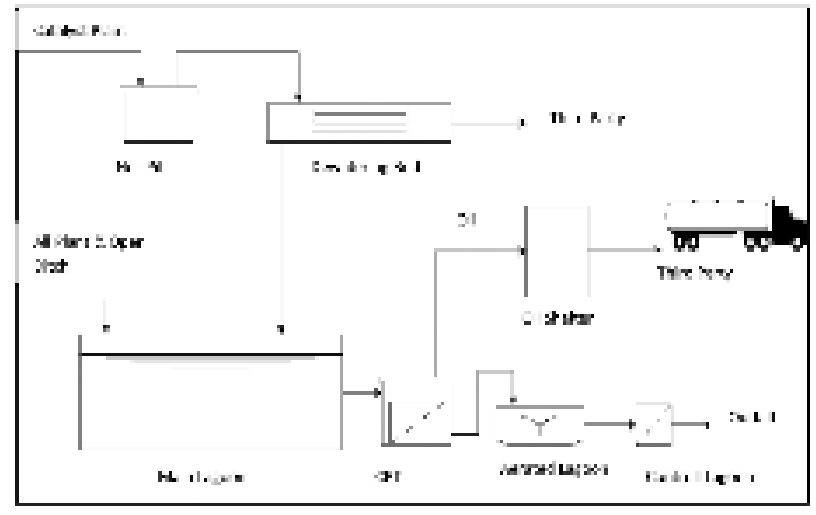

Gambar 5. Layout pengolahan air limbah

Lingkungan Hidup Nomor 22 Tahun 2011 tentang Izin Pembuangan Air Limbah ke laut PT Titan Petrokimia Nusantara. Analisa dari hasil uji laboratorium ini dilakukan untuk mengetahui persentase efektifitas dari proses ETU.

Efektifitas ETU menunjukkan keberhasilan dalam pengolahan air limbah sebelum adanya proses pengolahan dan sesudah proses pengolahan. Efektivitas proses ETU di PT LCTN dapat dilihat pada Tabel 4.

Persentase (\%) efektivitas diperoleh dari data inlet dan outlet. Contoh perhitungan berikut menggunakan parameter TDS pada bulan Januari 2015. Diketahui nilai analisa TDS pada proses inlet yaitu $680 \mathrm{mg} / \mathrm{l}$ dan analisa pada proses outlet yaitu $45 \mathrm{mg} / \mathrm{l}$. Selanjutnya dihitung menggunakan rumus berikut, dimana A merupakan parameter inlet, dan B merupakan parameter outlet.

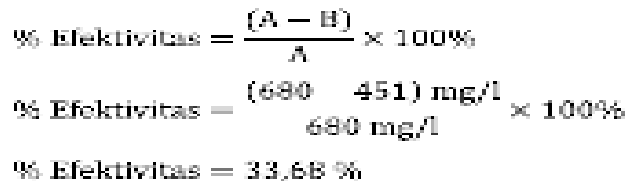

\subsection{Efektifitas penurunan kadar TDS (Total Disolved Solid)}

Analisa statistik SPSS menunjukkan rata-rata analisa inlet dan outlet TDS adalah -238,125 dengan satandar deviasi 514,856. Hasil menunjukkan terdapat perbedaan antara data inlet dan data outlet karena nilai t hitung $(-1,602)$ lebih kecil dari pada $t$ tabel (2,201). Dengan kata lain dapat memberikan pengaruh yang significant terhadap perbedaan data inlet dan outlet seperti nilai inlet lebih tinggi dari pada nilai outlet ataupun sebaliknya. 
Tabel 1. Hasil analisis Inlet

\begin{tabular}{|c|c|c|c|c|c|c|}
\hline \multirow[t]{3}{*}{$\begin{array}{l}\text { 7. Alum Amalis } \\
130.51\end{array}$} & \multicolumn{6}{|c|}{ 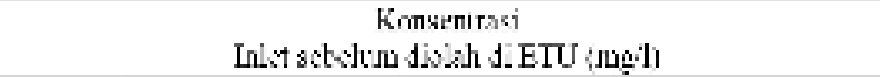 } \\
\hline & IDS & TSS & Nitcat & Nitrit & BUD & CODI \\
\hline & 4000 & 400 & 30 & 3 & 150 & 300 \\
\hline Januari & 680 & 30,5 & 2,15 & 0,0014 & $50, \mathrm{i}$ & 125.6 \\
\hline Feไtาเiลari & 251 & 80,5 & 0,49 & 1,17 & 50.24 & 89,65 \\
\hline Mide. & $4 \times 5$ & 361 & 2.68 & 11.46 & 69,2 & 145,6 \\
\hline April & 312 & 71,5 & 8,55 & 0,71 & 39.75 & $(2,0 !$ \\
\hline Mri & 118 & 675 & 1.17 & 11.31 & 101,88 & 212,77 \\
\hline$J_{u} n i$ & $25 t i$ & 51 & 2,13 & $n_{0} 0 ?$ & 16,88 & 35,27 \\
\hline Juli & 219 & 34 & 1,99 & $0.2 \%$ & 24.88 & 51,47 \\
\hline Ag.uslus & 852 & 6190 & 1,51 & $n_{3}, 01$ & 491 & $|021,4|$ \\
\hline Seplember & 385 & 332 & 4,69 & $1,3 !$ & 114 & 245 \\
\hline Oklober & 345 & 133 & 7.61 & 1.60 & 42.79 & $8 x .74$ \\
\hline Noventer & 680 & 542 & 0.95 & 0.82 & $13 \times, 75$ & 287.95 \\
\hline Desenter & 644 & 69 & 2.25 & 11.37 & 56,60 & 118 \\
\hline
\end{tabular}

Penurunan kadar TDS pada proses ETU di PT LCTN pada tahun 2015 kurang efektif karena sebagian besar memiliki nilai minus (-) yang menunjukkan nilai inlet lebih kecil daripada nilai outlet. Hal ini terjadi pada bulan April, Mei, Juni, Agustus, September, Oktober, Nopember, Desember. Penurunan kadar TDS seharusnya nilai outlet lebih kecil dari inlet. Penurunan TDS efektif pada bulan Januari sebesar 33,68\%, bulan Februari sebesar 54,33\%, bulan Maret 16,19\% dan bulan Juni sebesar 66,21\%. Terdapat 4 bulan yang efektif, maka selama tahun 2015 persentase bulan efektivitas mencapai 33,33\%.

\subsection{Efektifitas penurunan kadar TSS (Total Suspended Solid)}

Analisa statistik SPSS menunjukkan rata-rata analisa inlet dan outlet TSS adalah 600,625 dengan standar deviasi 1766,297.Hasil menunjukkan terdapat perbedaan antara data inlet dan outlet karena nilai t hitung $(1,192)$ lebih kecil daripada $t$ tabel $(2,201)$. Dengan kata lain, dapat memberikan pengaruh yang significant terhadap perbedaan data inlet dan data outlet seperti nilai inlet lebih tinggi daripada nilai outlet ataupun sebaliknya.

Penurunan kadar TSS pada proses ETU di PT LCTN selama tahun 2015 menunjukkan data sebagian besar sudah efektif karena hasil analisa outlet lebih rendah dari pada analisa inlet. Penurunan kadar TSS tidak efektif karena hasil analisa outlet lebih rendah daripada analisa inlet. Penurunan kadar TSS tidak efektif terjadi pada bulan April karena memiliki nilai minus (-) yang menunjukkan nilai inlet lebih kecil daripada nilai

Tabel 2. Hasil analisis outlet

\begin{tabular}{|c|c|c|c|c|c|c|}
\hline \multirow[t]{3}{*}{$\begin{array}{l}\text { Bulatil Aralixa } \\
(20.5)\end{array}$} & \multicolumn{6}{|c|}{$\begin{array}{c}\text { Konscntrasi } \\
\text { Oulel sebelum diulab di L IU (1us; } 1)\end{array}$} \\
\hline & TDS & TSS & Viirat & Yitrit & BOD & $C O D$ \\
\hline & 4060 & 400 & 30 & 3 & 150 & 300 \\
\hline Jапшаті & 451 & 22,5 & 0.9 & 0.004 & 34,25 & 71.27 \\
\hline lebruari & 116 & 81,5 & 4.16 & 127 & 19.88 & 41.53 \\
\hline Maret & 106.5 & 319 & 1,22 & 0,12 & 11,25 & 92.39 \\
\hline April & 448 & 185 & 8.58 & 0.70 & 37.25 & 77.76 \\
\hline Sci & $3 \%$ & 60 & 5,75 & 0,30 & 28,25 & 58.51 \\
\hline Juni & $3<3$ & 12 & 0,84 & 784 & 20,38 & 42.53 \\
\hline Juli & 74 & $3 y$ & 1.35 & 11,74 & 17.13 & 35,71 \\
\hline A & 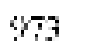 & 6 & 5,17 & 1.10 & 51.5 & 112,77 \\
\hline September & 477 & $2 \mathrm{~K} \%$ & $1 K, 14$ & $1.5 \mathrm{~K}$ & h4, ؟ & 134,54 \\
\hline Okınher & 1191 & 1.3 & 8,41 & 1,04 & $10 \dot{x}$ & 22.51 \\
\hline Norewber & $1(\infty)$ & 235 & 3,15 & 0.004 & 95.5 & 201,09 \\
\hline Desember & 2214 & 23 & 3,38 & 2,11 & 18,63 & 39 \\
\hline
\end{tabular}


Tabel 3. Hasil uji SPSS Statistik Inlet-Outlet

\begin{tabular}{|c|c|c|c|c|c|c|c|}
\hline $\begin{array}{l}\text { Uji } \\
\text { Inlet- } \\
\text { Oullel }\end{array}$ & Me:ll & $\begin{array}{c}\text { Sld. } \\
\text { Deriation }\end{array}$ & $\begin{array}{c}\text { Sid I reer } \\
\text { Mcan }\end{array}$ & I & $\mathrm{dr}$ & $\begin{array}{l}\text { Sent? } \\
\text { (uilod) }\end{array}$ & $\begin{array}{c}1 \\
\text { tabsl }\end{array}$ \\
\hline TDS & $-238,125$ & 514,856 & 148,626 & $-1,602$ & 11 & 0.137 & 2.201 \\
\hline TSS & 607625 & 1766,297 & Sto.s8ti & 1,192 & 11 & 0,258 & 2,201 \\
\hline Nitrat & $-2,882$ & 4,276 & 1,234 & $-2,335$ & 11 & 0,04 & 2.201 \\
\hline Nitril & -0.734 & 2,322 & 0.670 & $-1,199.5$ & 11 & 0,297 & 2,201 \\
\hline $\mathrm{BOD}$ & 61,509 & 120,589 & $21, \bar{x} \mid 1$ & 1.767 & 11 & 0.105 & 2,201 \\
\hline COD & $12 \%, 455$ & 249,839 & 72.122 & 1.795 & 11 & 0,1 & 2.201 \\
\hline
\end{tabular}

outlet. Penurunan TSS terjadi pada 11 (sebelas) bulan sudah efektif, maka selama tahun 2015 persentase bulan efektivitas mencapai 91,67\%.

\subsection{Efektifitas Penurunan Kadar Nitrat}

Analisa statistik SPSS menunjukkan rata-rata analisa inlet dan outlet nitrat adalah -2,882 dengan standar deviasi 4,267. Hasil menujukkan terdapat perbedaan antara data inlet dan data outlet karena nilai t hitung $(-2,335)$ lebih kecil daripada $t$ tabel (2,201). Dengan kata lain dapat memberikan pengaruh yang significant terhadap perbedan data inlet dan data outlet seperti nilai inlet lebih tinggi daripada nilai outlet ataupun sebaliknya.

Penurunan kadar nitrat pada proses ETU di PT LCTN selama tahun 2015 kurang efektif karena sebagian besar memiliki nilai minus (-) yang menunjukkan nilai inlet lebih kecil daripada nilai outlet. Hal itu terjadi pada bulan Februari, April, Mei, Juni, September, Oktober, November, dan Desember. Penurunan kadar nitrat seharusnya nilai outlet lebih kecil daripada inlet. Penurunan nitrat efektif pada bulan Januari sebesar 58,14\%, bulan Maret 50,73\% dan bulan Juni sebesar $32,16 \%$. Penurunan nitrat terjadi pada 3 (tiga) bulan yang efektif, maka selama tahun 2015 persentase bulan efektivitas mencapai 25\%. Nitrat yang tidak sempurna dapat menyebabkan kualitas air menurun, menurunkan oksigen terlarut, penurunan populasi ikan, bau busuk, dan rasa tidak enak.

\subsection{Efektivitas Penurunan Kadar Nitrit}

Analisa statistik SPSS menunjukkan rata-rata analisa inlet dan outlet nitrit adalah -0,734 dengan standar deviasi 0,67. Hasil menunjukkan terdapat

Tabel 4. Efektivitas pengolahan air limbah periode tahun 2015 di PT LCTN

\begin{tabular}{|c|c|c|c|c|c|c|}
\hline \multirow{2}{*}{$\begin{array}{c}\text { Hulau ingl|sil } \\
\{2015\rangle\end{array}$} & \multicolumn{6}{|c|}{ lefelivilas (s) } \\
\hline & TTSS & TSS & Vilmal & Viıril & $\mathrm{B} \cap \mathrm{D}$ & (O) \\
\hline Jamuarj & 33.68 & 26,23 & 58.14 & ॥ & 32,21 & 43,26 \\
\hline Felhrıагі & 54,33 & 23.6 & $-748,98$ & 13,61 & 60,43 & 53.68 \\
\hline Murst & 16,19 & 3,12 & 50,75 & 73.91 & 32.13 & 36,55 \\
\hline ispril & $-30,9 y$ & $-158,74$ & $-0,35$ & 1.41 & -25.21 & $-25,4$ \\
\hline Mei & -161.86 & 91,11 & $-391,45$ & 2.23 & 72.27 & 72.5 \\
\hline Jwi & $-41,8$ & 76,47 & $-381,97$ & -11100 & -20.73 & -20.58 \\
\hline Juli & $\mathrm{Ci}_{i}, 21$ & $|1,7|$ & 32,16 & 17,21 & 31.15 & 30,62 \\
\hline Agusrus & 14,2 & 99,9 & -242.38 & $-10 x$ & $\$ \% .1$ & 88,96 \\
\hline Sejremher & $-2.9,9$ & $15,06 i$ & $-2 \times 6,78$ & $-13,67$ & 43.42 & 15,09 \\
\hline Oxtolyer & -40.95 & 90,23 & $-10,51$ & .35 & 74.74 & 74,62 \\
\hline Novemiler & $-135,94$ & 56,64 & $-792,63$ & 44.\$1 & 31,17 & 30,16 \\
\hline Deximber & $-241: 14$ & tidi, ${ }^{2}$ ? & $-6 \dot{x}$ & $-470,27$ & 67,03 & tidi,95 \\
\hline Hulau telectatî & 4 bukitr & II buları & "3 buklar & 7 bulau & 10 bulan & $\begin{array}{c}10 \\
\text { bulan }\end{array}$ \\
\hline $\begin{array}{l}\text { Bulun Tidak } \\
\text { Elekıi }\end{array}$ & 8 bulan & 1 buku & 9 buka & 5 bulan & 2 bulut & 2 bulu \\
\hline $\begin{array}{l}\text { Lelekltrilias Sulatmil } \\
\text { Tahun } 2015\end{array}$ & 33.33 & 41,67 & 25 & 58.33 & 53,33 & 83,33 \\
\hline
\end{tabular}




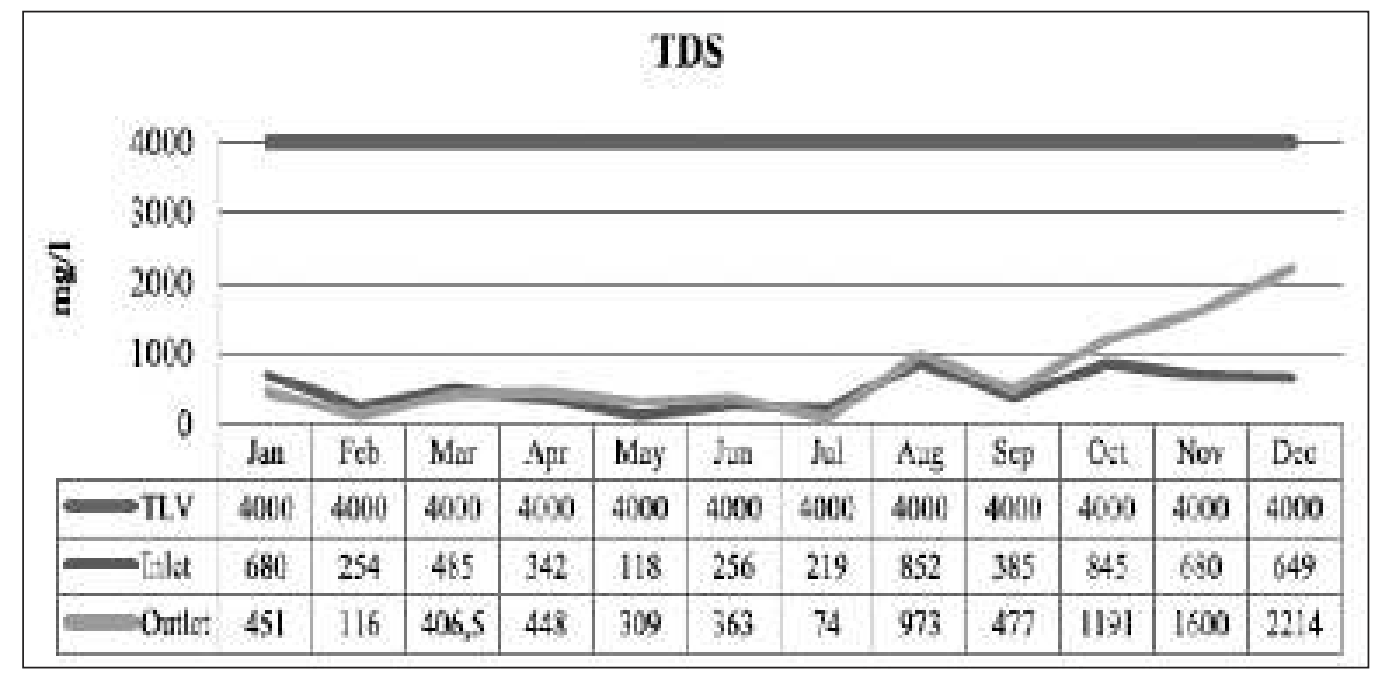

Gambar 6. Grafik hasil analisa TDS

perbedaan antara data inlet dan data outlet karena nilai $t$ hitung $(-1,095)$ lebih kecil daripada t tabel $(2,201)$. Dengan kata lain dapat memberikan pengaruh yang significant terhadap perbedan data inlet dan data outlet seperti nilai inlet lebih tinggi daripada nilai outlet ataupun sebaliknya.

Penurunan kadar nitrit pada proses ETU di PT LCTN selama tahun 2015 menunjukkan data sebagian besar sudah efektif karena hasil analisa outlet lebih rendah dari pada analisa inlet. Terdapat beberapa bulan yang tidak efektif karena sebagian besar memiliki nilai (-) minus yang menunjukkan nilai inlet lebih kecil dari pada nilai outlet.

\subsection{Efektivitas Penurunan kadar BOD (Bioche- mical Oxygen Demand)}

Analisa statistik SPSS menunjukkan ratarata analisa inlet dan outlet BOD adalah 61,509 dengan standar deviasi 120,589. Hasil menunjukkan terdapat perbedaan antara data inlet dan data outlet karena nilai t hitung $(1,767)$ lebih kecil dari t tabel $(2,201)$. Dengan kata lain, dapat memberikan pengaruh yang signifikan terhadap perbedaan data inlet dan outlet seperti nilai inlet lebih tinggi dari pada nilai outlet ataupun sebaliknya.

Penurunan kadar BOD pada proses ETU di PT LCTN selama tahun 2015 menunjukkan data sebagian besar sudah efektif karena hasil

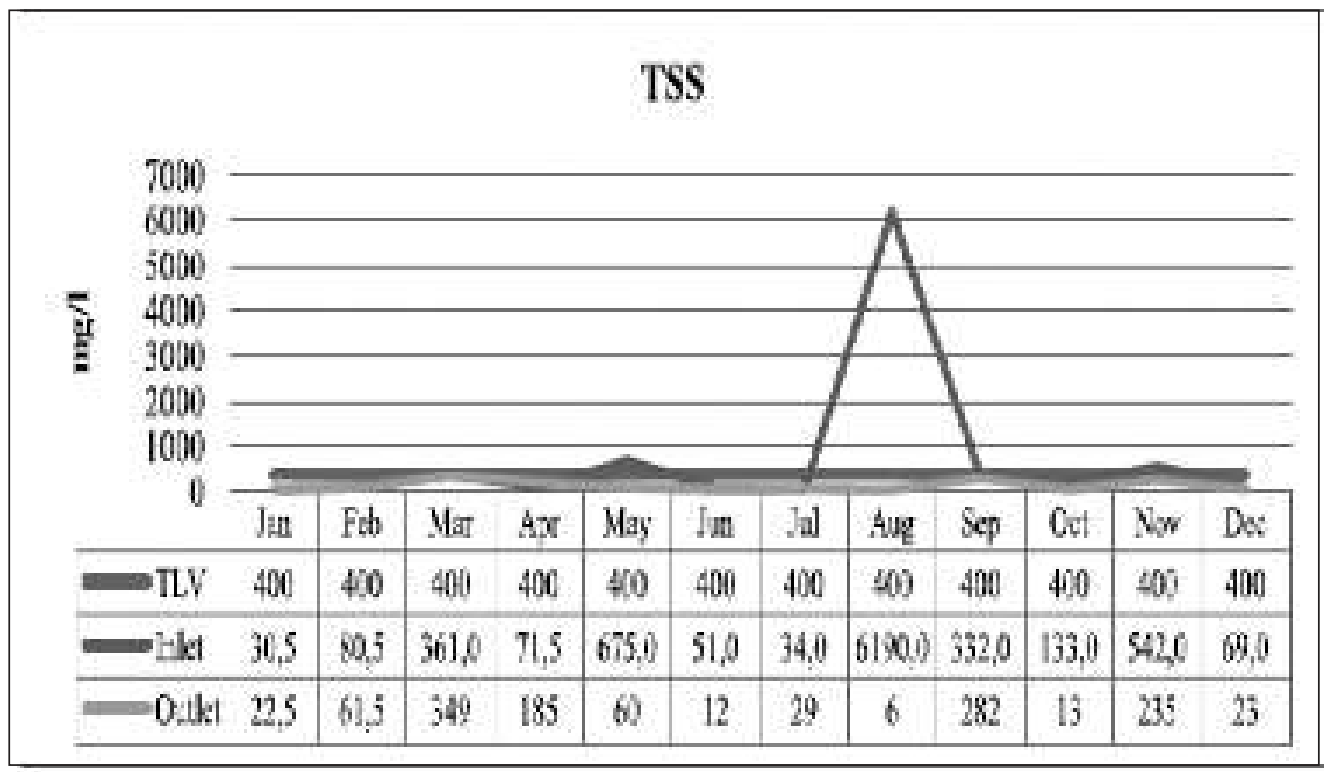

Gambar 7. Grafik hasil analisa TSS 


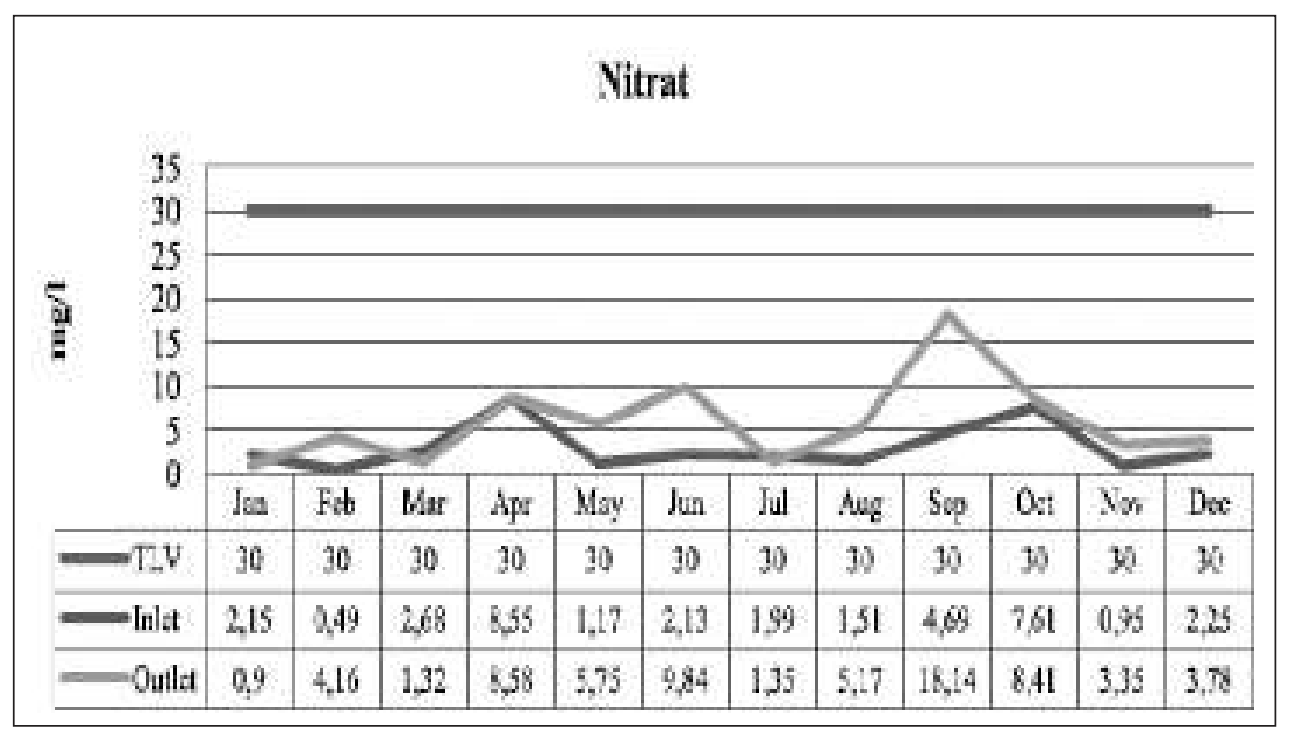

Gambar 8. Grafik hasil analisa nitrat

analisa outlet lebih rendah dari pada analisa inlet. Penurunan kadar BOD tidak efektif terjadi pada bulan April dan Juni karena memiliki nilai minus (-) yang menunjukkan nilai inlet lebih kecil daripada nilai outlet. Penurunan BOD terjadi pada 10 (sepuluh) bulan yang efektif, maka selama tahun 2015 persentase bulan efektivitas 83,33\%.

\subsection{Efektivitas penurunan kadar COD (Chemical Oxygen Demand)}

Analisa statitik SPSS menunjukkan ratarata analisa inlet dan outlet COD adalah 129,455 dengan standar deviasi 249,839. Hasil menunjukkan terdapat perbedaan antara data inlet dan outlet karena nilai t hitung $(1,795)$ lebih kecil daripada t tabel $(2,201)$. Dengan kata lain, dapat memberikan pengaruh yang signifikan terhadap perbedaan data inlet dan outlet seperti nilai inlet lebih tinggi dari pada nilai outlet ataupun sebaliknya.

Sama halnya seperti penurunan kadar BOD, penurunan kadar COD pada proses ETU di PT LCTN selama tahun 2015 menunjukkan data sebagian besar sudah efektif karena hasil analisa outlet lebih rendah daripada analisa inlet. Penurunan kadar BOD tidak efektif terjadi pada bulan April dan Juni karena memiliki nilai minus (-) yang menunjukkan nilai inlet lebih kecil daripada nilai outlet. Penurunan BOD terjadi pada 10 (sepuluh) bulan yang efektif, maka selama

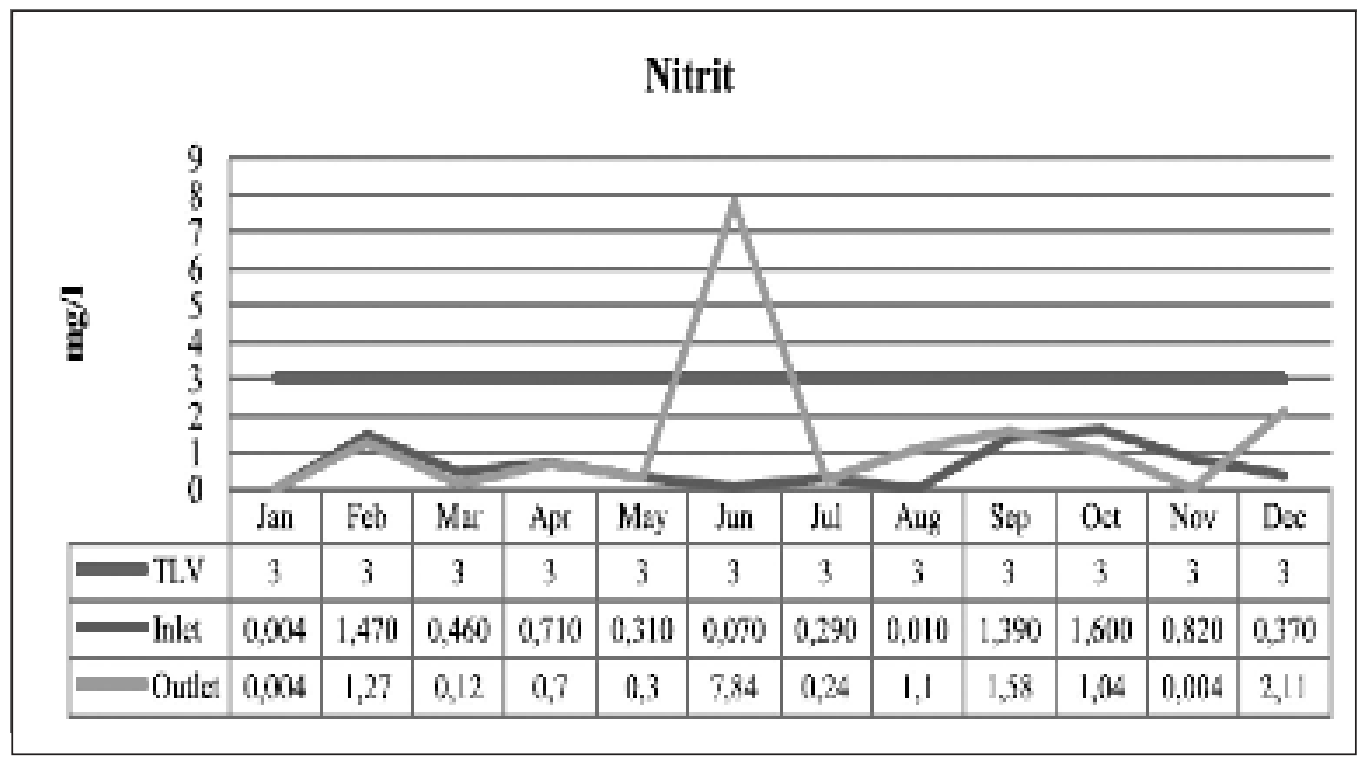

Gambar 9. Grafik hasil analisis nitrit 


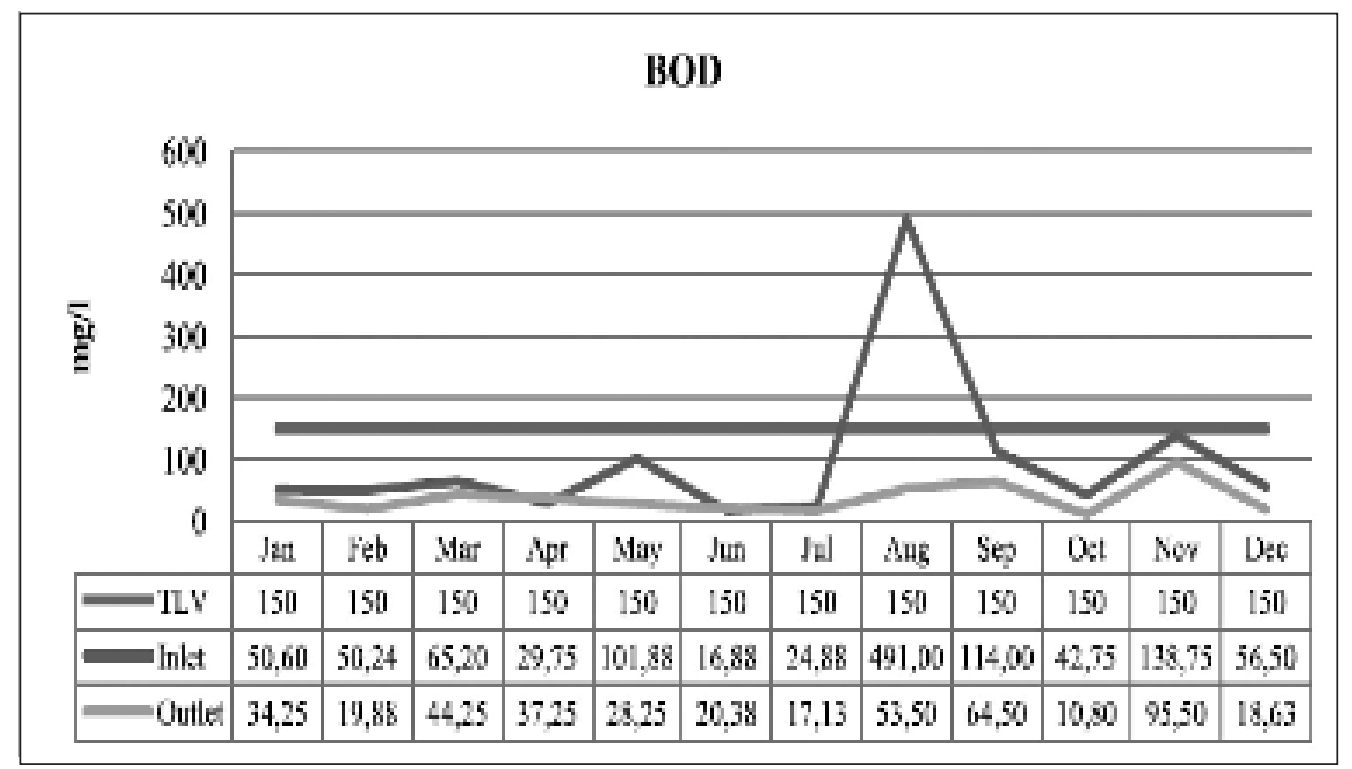

Gambar 10. Grafik hasil analisis BOD

tahun 2015 persentase bulan efektivitas $83,33 \%$.

\subsection{Langkah perbaikan Pengolahan Air Limbah Proses ETU PT LCTN}

Pengolahan air limbah pada ETU PT LCTN memiliki efektivitas yang berbeda-beda. Nilai efektivitas dihitung dari persentase (\%) penurunan kandungan TDS, TSS, nitrat, nitrit, BOD, dan COD. Hasil analisa yang dilakukan sebelum diproses pada ETU (inlet) terdapat hasil yang menunjukkan nilai lebih rendah dari pada setelah di proses pada ETU (outlet). Hal tersebut karena adanya adanya hambatan atau kendala pada setiap unit pengolahan, seperti padatan yang belum tersaring sempurna, bahan organik yang belum terurai sempurna. Beberapa permasalahan dan langkah perbaikan pada pengoperasian Effluent Treatment Unit (ETU) dapat dilihat pada tabel berikut :

Secara keseluruhan perlu dilakukan upaya atau langkah-langkah perbaikan, diantaranya sebagai berikut :

1. Alat ukur debit inlet

Perlu memasang alat ukur debit inlet pada proses main lagoon berupa alat V-notch. Debit inlet berfungsi sebagai pembanding debit outlet.

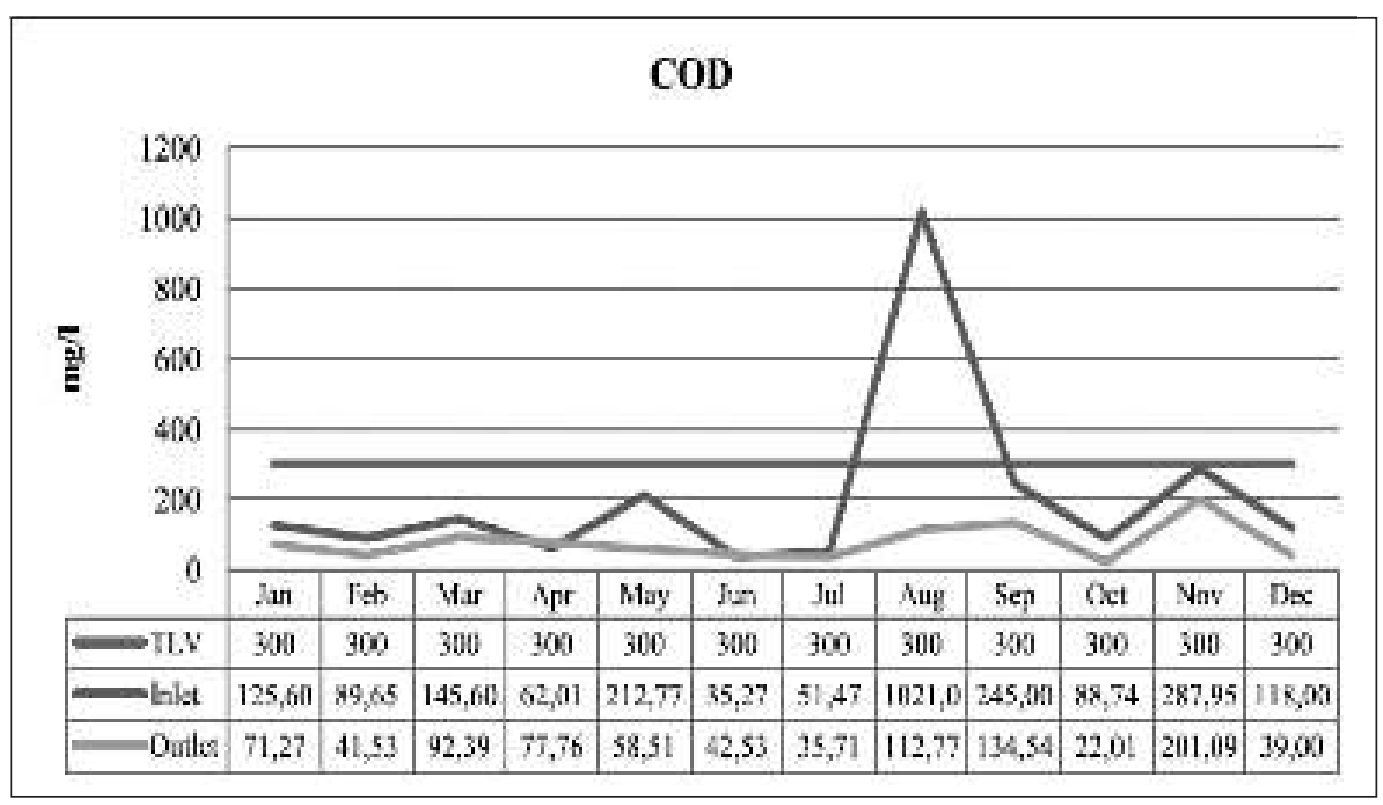

Gambar 11. Grafik hasil analisis COD 
Tabel 5. Permasalahan dan langkah perbaikan pada proses ETU

\begin{tabular}{|c|c|c|c|}
\hline Nu. & Uuil & Permalsilialoir & 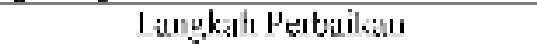 \\
\hline 1. & Aain ingoon & 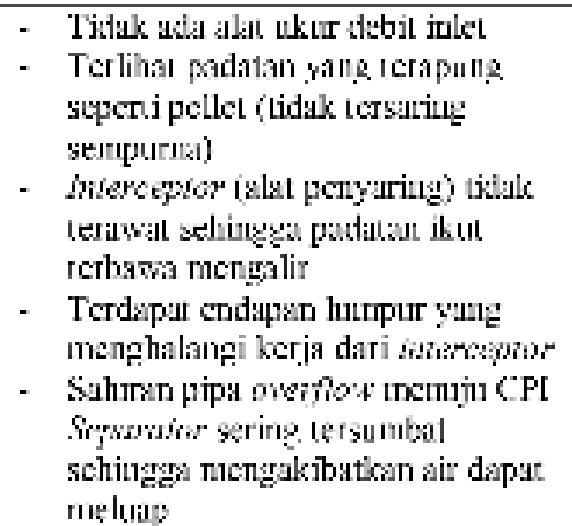 & 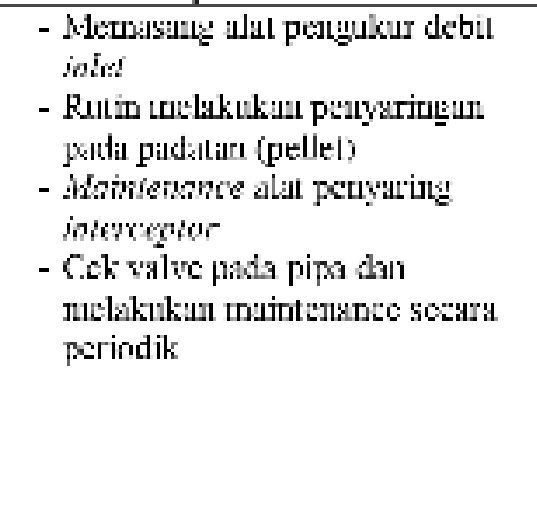 \\
\hline 2. & СТ Tequation & 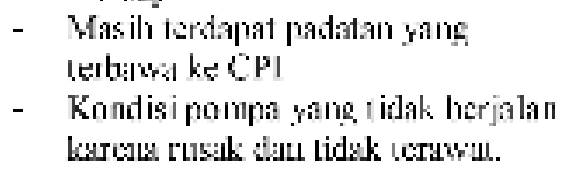 & 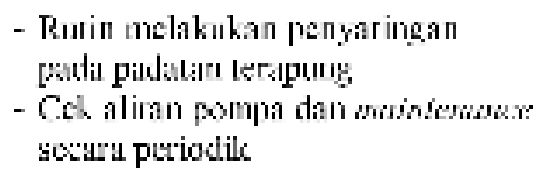 \\
\hline 3 & Aequised Gizion & 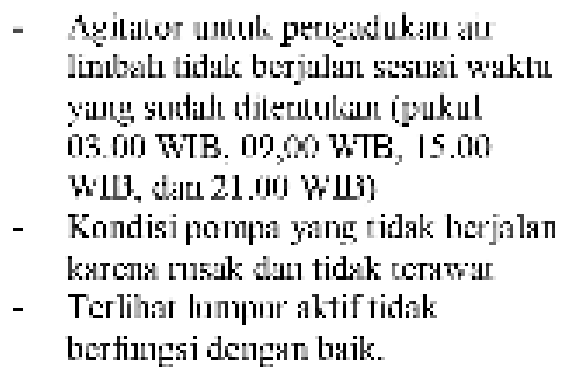 & 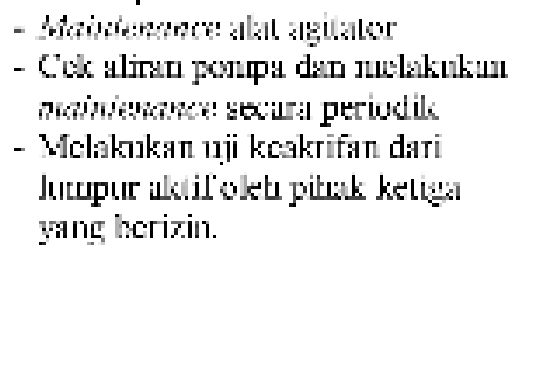 \\
\hline
\end{tabular}

Sumber: Analisis, 2016

2. Penambahan proses penyaringan

Penyaringan bertujuan untuk mengurangi padatan maupun lumpur tercampur dan partikel koloid dari air limbah.Hal ini dapat membantu menanggulangi parameter TDS dan TSS. Penyaringan yang diterapkan di kolam main lagoon adalah interceptor namun kondisinya tidak berjalan baik dan perlu adanya perbaikan khusus.

3. Melakukan uji keaktifan lumpur aktif (activated sludge)

Unit lumpur aktif dengan sistem aerasi menggunakan mikroba yang telah terseleksi yang cocok dengan kontaminan limbah yang ada, yang dikembangkan dari limbah itu sendiri. Aerasi menggunakan blower dan udara dialirkan melalui diffuser agar distribusi oksigen lebih merata.Penerapan di PT LCTN sudah menggunakan sistem lumpur aktif pada proses aerated lagoon, tetapi perlu dilakukan pengujian pada laboratorium eksternal untuk mengetahui kondisi lumpur aktif.
4. Pemberian ikan pada bak kontrol sebagai indikator.

Air limbah yang sudah diproses pada ETU akan lebih baik jika diuji terlebih dahulu menggunakan biota air yaitu ikan kecil-kecil. Ikan mas dan/ikan nila merupakan jenis ikan yang memiliki sensitifitas tinggi terhadap perubahan lingkungan. Oleh karena itu ikan mas dan/ikan nila dapat digunakan sebagai indikator keberhasilan pengolahan air limbah pada unit ETU.

5. Maintenance atau perawatan unit ETU

Apabila kondisi proses ETU sudah berjalan dengan baik maka perlu dilakukan perawatan secara berkala untuk menghindari terjadinya kerusakan atau kesalahan proses. Perawatan unit ETU perlu dukungan pihak manajemen perusahaan dan sumber daya manusia. Unit ETU tidak memerlukan perawatan yang khusus, tetapi ada beberapa hal yang perlu diperhatikan antara lain :

a. Sedapat mungkin tidak ada minyak, 
pellet,bubuk pellet, dan sampah lainnya pada setiap unit ETU

b. Bak kontrol harus dibersihkan secara rutin minimal satu minggu sekali atau lebih baik sesering mungkin untuk menghindari terjadinya penyumbatan oleh sampah padat.

c. Menghindari masuknya zat-zat kimia beracun yang dapat mengganggu pertumbuhan mikroba yang ada dalam aerated laggon.

d. Perlu dilakukan pengurasan lumpur pada main lagoon dan aerated lagoon dan secara periodik untuk menguras lumpur yang tidak dapat terurai secara biologis.

e. Perawatan rutin pompa dan blower udara menyesuaikan pada SOP dan Instruksi kerja PT LCTN.

\section{Kesimpulan}

Unit pengolahan air limbah di PT LCTN melalui proses Effluent Treatment Unit (ETU) dirancang untuk mengolah limbah yang mengandung pencemar. Hasil eksisting atau keluaran air limbah ke badan air, beberapa parameter uji sudah sesuai dengan dam masih ada yang tidak sesuai baku mutu. Langkah perbaikan meliputi pemeliharaan ETU dan perbaikan lain secara teknis seperti penambahan alat ukur debit inlet, penambahan proses penyaringan, uji keaktifan lumpur aktif dan pemberian ikan pada bak kontrol.

\section{Daftar Pustaka}

Arikunto,2006. Seri Belajar Praktis Menguasai SPSS 13 untuk Statistik. Jakarta. Salemba Infotek.

Asmadi dan Suharno.2012.Dasar-dasar Teknologi Pengolahan Air Limbah.Yogyakarta. Gosyen Publishing.

Idaman Said, Nusa dan Wahyu Hidayat, 2008. Pengolahan Air Limbah Domestik di DKI Jakarta: Tinjauan Permasalahan, Strategi dan Teknologi Pengolahan. Jakarta Pusat. Pusat Teknologi Lingkungan BPPT.

Keputusan Menteri Lingkungan Hidup Nomor 22,2011. Tentang Izin Pembuangan Air Limbah ke Laut PT Titan Petrokimia Nusantara.Jakarta.

Metcalf \& Edy, Inc.1991. Waste Water Engineering treatment, disposal and reuse .3 rd ed. New York. Mc Graw Hil Inc.

Peraturan Menteri Lingkungan Hidup RI No.

5 Tahun 2014 Tentang Baku Mutu Air Limbah. Jakarta. Sekretariat Negara.

Samina, 2013. Efektivitas Instalasi Pengolahan Air Limbah (IPAL) Domestik di Kota Cirebon Terhadap Penurunan Pencemar Organik dan E-Coli. Jurnal Ilmu Lingkungan Program Pasca Sarjana. Semarang. Universitas Diponegoro.

Siregar, Sakti A.2005. Instalasi Pengolahan Air Limbah. Yogyakarta. Kanisius.

Suparmin, Soeparman, 2001. Pembuangan

Tinja dan Limbah Cair. Buku Kedokteran EGC, Jakarta. 